\title{
Neonatal Primary Panhypopituitarism Presenting as Shock
}

\author{
Anita Singh ${ }^{1 *}$, Neelam Kler ${ }^{2}$, Pankaj Garg² and Anup Thakur ${ }^{2}$ \\ ${ }^{1}$ Department of Neonatology, Sanjay Gandhi Postgraduate Institute of Medical Sciences, India \\ ${ }^{2}$ Department of Neonatology, Institute of Child Health, India
}

*Corresponding author: Anita Singh, Assistant professor (Neonatology), Sanjay Gandhi Postgraduate Institute of Medical Sciences, Lucknow, Uttar Pradesh, India

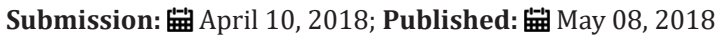

\begin{abstract}
Neonatal shock is a life-threatening emergency with high mortality. There could be multiple etiologies of neonatal shock. Neonatal hypopituitarism is one of the rare but treatable causes of refractory neonatal shock. Hypoglycemia and dysmorphic features can be clue to endocrinal pathology. With a high index of suspicion and prompt supportive management, it is possible to manage such cases effectively and prevent mortality.

Keywords: Neonatal; Panhypopituitarism; Shock

Abbreviations: MAP: Mean Airway Pressure; FiO2: Fractional Concentration of Inspired Oxygen; GIR: Glucose Infusion Rate; TSH: Thyroid Stimulating Hormone; MRI: Magnetic Resonance Imaging; DASII: Developmental Assessment Scale for Indian Infants; MDI: Mental Development Index; PDI: Psychomotor Development Index
\end{abstract}

\section{Introduction}

Hypopituitarism is partial or complete insufficiency of pituitary hormone secretion. Etiology of hypopituitarism is varied and onset may occur at any time from neonatal to adult age group. Early presentation of hypopituitarism in neonate or infant is manifested with features like mid facial hypoplasia, micropenis, resistant hypoglycemia or prolongation of hyperbilirubinemia. Etiology could be congenital or acquired. Presentation as shock in the neonate is rare. Early recognition and prompt management of the condition helps in preventing life threatening complications.

\section{Case Presentation}

We report a 6 days old female newborn presenting with respiratory distress, hypoglycemia and refractory shock. The neonate was born out of consanguineous marriage (second-degree relatives) and was the third child of the couple. The first child was three and a half years old and healthy. The second child died at the age of 5 months due to pneumonia. The present pregnancy was complicated with polyhydramnios. Mother underwent cesarean section at 36 weeks of gestation for fetal bradycardia. Baby cried immediately after birth and did not require active resuscitation. Her birth weight, length and head circumference were $2750 \mathrm{gm}\left(63^{\text {rd }}\right.$ centile), $49 \mathrm{~cm}$ ( $58^{\text {th }}$ centile) and $35 \mathrm{~cm}$ ( $70^{\text {th }}$ centile) respectively on Fenton growth charts. Soon after birth, the infant developed respiratory distress requiring ventilator support and surfactant replacement therapy at $4 \mathrm{hrs}$ of age. Eventually, the baby developed shock and was transferred to our institute on day 6 of life.
At admission, the infant was in shock, and neurologically depressed. She required mechanical ventilation with mean airway pressure (MAP) of $8-10 \mathrm{~m}$ bar and fractional concentration of inspired oxygen (FiO2) of 0.3-0.6. Baby had hypoglycemia with a blood sugar $36 \mathrm{mg} / \mathrm{dl}$ and was started on intravenous glucose with a glucose infusion rate (GIR) of $10 \mathrm{mg} / \mathrm{kg} / \mathrm{min}$. In view of the clinical possibility of septic shock, sepsis work up was sent and empirical antibiotics were started along with inotropes. Echocardiography revealed ejection fraction of $30 \%$ with poor contractility. On further examination, there was facial dysmorphism in the form of coarse features, protruded tongue and mid facial hypoplasia (Figure 1). Anterior fontanel was wide measuring $6.2 \times 7.3 \mathrm{~cm}$. Fund us examination was normal. Despite three inotropes (dopamine, dobutamine and adrenaline) in maximum doses, the baby remained hypotensive. She was treated with intravenous hydrocortisone $10 \mathrm{mg} / \mathrm{kg} /$ day for treatment of catecholamine-resistant shock as per unit protocol. In view of facial dysmorphism, wide anterior fontanels and catecholamine-resistant shock, serum cortisol level (before the first dose of hydrocortisone) and thyroid profile were sent. Liver function tests were also sent and were normal. Serum Ammonia, creatinine phosphokinase and karyotype analysis were done as the baby was in encephalopathy with generalized hypotonia along with features of dysmorphism. Serum cortisol level was low $(2.68 \mu \mathrm{g} / \mathrm{dl})$ and thyroid profile revealed low free T3 $(0.82 \mathrm{pg} / \mathrm{ml})$, free T4 $(0.25 \mathrm{ng} / \mathrm{dl})$ along with low TSH $(0.049 \mu \mathrm{IU} / \mathrm{ml})$. She was also started on thyroxine $(15 \mathrm{mcg} / \mathrm{kg} /$ day $)$ for hypothyroidism. 
In view of hypocortisolism and secondary hypothyroidism, a possibility of hypopituitarism was kept and the baby was further evaluated (Table 1). Blood culture taken at admission grew Candida parapsilosis, which was treated with intravenous Amphotericin B for 3 weeks. Karyo typing and metabolic screen sent at admission were normal. The baby could be weaned off inotropes and mechanical ventilation within $72 \mathrm{hrs}$ of starting hydrocortisone and thyroxine. Hydrocortisone was switched to oral dose after blood pressure normalized. Repeat echocardiography showed normal ejection fraction.

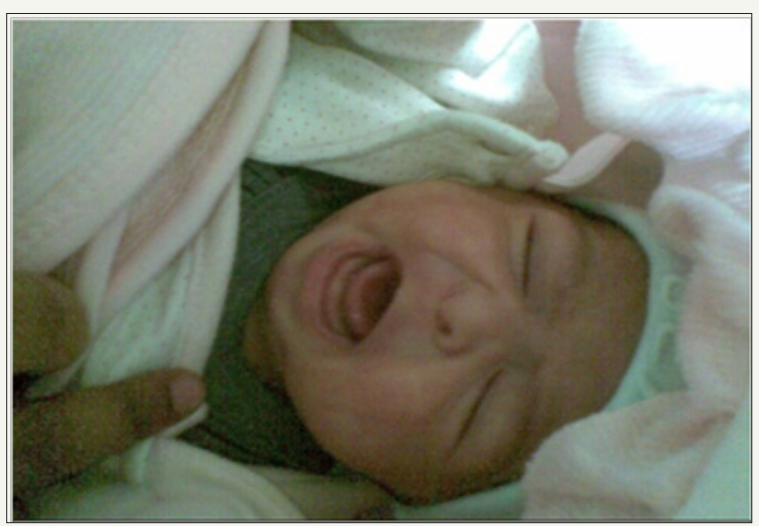

Figure 1: Bilateral gynecomastia (Left > right).

Table 1: Laboratory evaluation of various hormones.

\begin{tabular}{|c|c|c|}
\hline & Test Value & Neonatal Reference Range \\
\hline Free T3 $(\mathrm{pg} / \mathrm{ml})$ & 0.82 & $2.34-6.2$ \\
\hline Free T4 $(\mathrm{ng} / \mathrm{dl})$ & 0.25 & $1.13-2.3$ \\
\hline TSH $(\mu \mathrm{IU} / \mathrm{ml})$ & 0.049 & $0.27-4.20$ \\
\hline Cortisol $(\mu \mathrm{g} / \mathrm{dl})$ & 2.68 & $6.20-19.4$ \\
\hline ACTH $(\mathrm{pg} / \mathrm{ml})$ & 0.8 & $8-63$ \\
\hline $\mathrm{LH}(\mathrm{IU} / \mathrm{ml})$ & 0.1 & $1-3.3$ \\
\hline FSH $(\mathrm{IU} / \mathrm{ml})$ & 0.1 & $1-7.1$ \\
\hline $\mathrm{E} 2(\mathrm{pg} / \mathrm{ml})$ & 18.84 & $42-134$ \\
\hline
\end{tabular}

T3: Triiodothyronine; T4: Thyroxine; TSH: Thyroid Stimulating Hormone; ACTH: Adrenocorticotropic Hormone; LH: Luteinizing Hormone; FSH: Follicle Stimulating Hormone; E2: Estradiol; GH: Growth Hormone
MRI braindoneto visualize pituitary fossa showed hypoplastic pituitary gland -craniocaudal height of $1.7 \mathrm{~mm}$ (normal craniocaudal pituitary height in the female neonate is $3.81 \pm 0.68$ ) [1], small pituitary fossa and dysgenesis of corpus callosum with a small area of gliosis in left frontal periventricular white matter (Figure 2). Visual evoked potentials and automated brainstem evoked responses were normal. Baby was discharged on oral hydrocortisone $\left(15 \mathrm{mg} / \mathrm{m}^{2}\right)$ and thyroxine $(15 \mu \mathrm{g} / \mathrm{kg} /$ day). Repeat thyroid profile and cortisol levels done periodically during followup were within normal range. At one year of age, the infant has weight, length and head circumference of $6.9 \mathrm{Kg}\left(<3^{\text {rd }}\right.$ centile $)$, $62 \mathrm{cms}\left(<3^{\text {rd }}\right.$ centile $)$ and $43 \mathrm{cms}\left(8^{\text {th }}\right.$ centile $)$ respectively on WHO growth standards. Neuro developmental follow up done on DASII (Developmental Assessment Scale of Indian Infants) [2] showed MDI (Mental developmental index) of 63 and PDI (Psychomotor developmental index) of 82 . The child is under follow up, on thyroxine, cortisol supplementation and rehabilitative care.

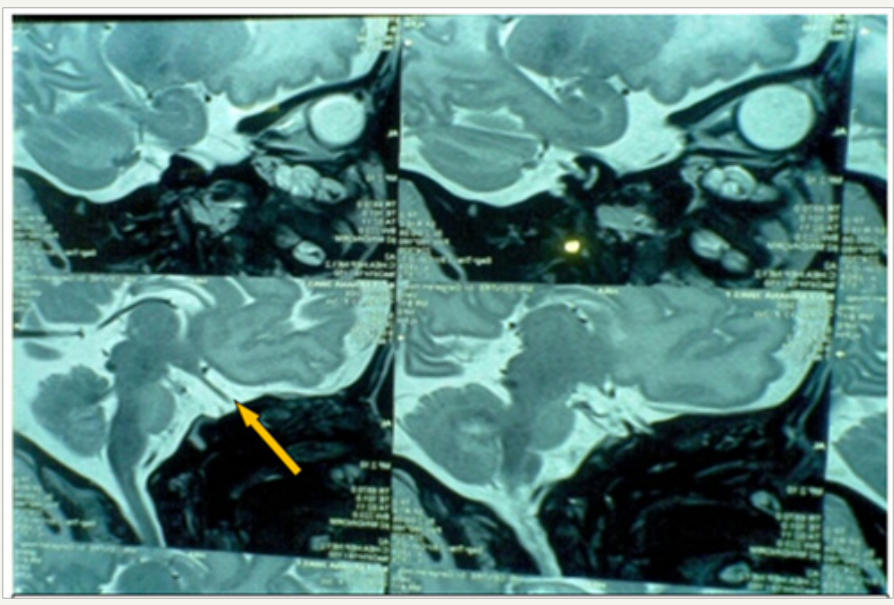

Figure 2: Hypoplastic pituitary gland (arrow) in T2 weighted sagittal section. 


\section{Discussion}

Neonatal panhypopituitarism with multiple hormonal deficiencies occurs in approximately 1 in 53,000 newborns [3]. Presences of facial dysmorphism like mid-facial hypoplasia, micropenis, resistant hypoglycemia, refractory shock or prolongation of hyperbilirubinemia are important pointers to this rare disorder. Diagnosis is more challenging in female neonates where features of hypogenitalism may not be apparent as was in our case. In a review of five cases of neonatal panhypopituitarism by Scommegna et al. [4], major clinical features were respiratory distress, metabolic acidosis, non-cholestatic jaundice, hypotonia, severe hypoglycemia, hypogenitalism and midline defects. In another report of congenital panhypopituitarism by Filges et al. [5], the presentation was life-threatening heart failure. Catecholamine refractory shock along with hypoglycemia and facial dysmorphism were the main presenting features in our case. Effect of deficiency of cortisol on blood pressure along with the impaired action of anti-diuretic hormone has been implicated as reasons for shock. In our case, the shock could have been further complicated because of concomitant fungal sepsis, though the baby showed remarkable recovery after hydrocortisone and thyroxine supplementation. In another case reported by Filges et al. [5], the child recovered of heart failure after replacement with hydrocortisone and thyroxine. Noninfectious hepatitis including cholestasis has also been reported as presenting features of congenital panhypopituitarism [6]. However in our case, liver function tests were normal.

Panhypopituitarism due to some acquired causes like perinatal asphyxia, birth trauma and septic infarction may present early after birth. There is a report of acquired hypopituitarism in a female neonate by Saranac et al with Salmonella enteritidis sepsis and cystic encephalomalacia after prolonged dopamine administration [7]. Though our baby had concomitant Candida parapsilosis sepsis but neuro imaging findings of small pituitary fossa along with associated corpus callosum dysgenesis confirmed the cause of hypopituitarism to be congenital. As this is a midline defect and as a part of septooptic dysplasia, it may involve abnormalities of the visual pathway, hence visual evoked potential study was done which was normal in our case. Septo-optic dysplasia, other midline defects and mutation in transcription factors involved in pituitary gland development are important causes of congenital panhypopituitarism. Genes responsible for congenital hypopituitarism are identified as LHX3, LHX4, PIT-1, PROP-1SOX3, SOX4, HESX1 and PC1 [8]. In the present case, genetic analysis could not be done.

\section{References}

1. Sari S, Sari E, Akgun V, Ozcan E, Ince S, et al. (2014) Measures of pituitary gland and stalk: from neonate to adolescence. J Pediatr Endocrinol Metab 27(11-12): 1071-1076.

2. Patni B (2012) Developmental assessment scales for indian infants (DASII). Indian Journal of Practical Pediatrics 14(4): 409-412.

3. Hanna CE, Krainz PL, Skeels MR, Miyahira RS, Sesser DE, et al. (1986) Detection of congenital hypopituitary hypothyroidism: ten-year experience in the northwest regional screening program. J Pediatr 109(6): 959-964.

4. Scommegna S, Galeazzi D, Picone S, Farinelli E, Agostino R, et al. (2004) Neonatal identification of pituitary a plasia: a life-saving diagnosis. Review of five cases. Horm Res 62(1): 10-16.

5. Filges I, Bisch of Renner A, Röthlisberger B, Pothoff C, Glanzmann R, et al (2012) Panhypopituitarism presenting as life-threatening heart failure caused by an inherited microdeletion in 1q25 including lhx4. Pediatrics 129(2): e529-e534.

6. Spray $\mathrm{CH}$, MckiernanP, Waldron KE, Shaw N, Kirk J, et al. (2000) Investigation and outcome of neonatal hepatitis in infants with hypopituitarism. Acta Paediatr 89(8): 951-954.

7. Saranac L, Bjelakovic B, Djordjevic D, Novak M, Stankovic T (2012) Hypopituitarism occurring in neonatal sepsis. J Pediatr Endocrinol Metab 25(9-10): 847-848.

8. Alatzoglou KS, Dattani MT (2009) Genetic forms of hypopituitarism and their manifestation in the neonatal period. Early Hum Dev 85(11): 705712.
Creative Commons Attribution 4.0 International License

For possible submissions Click Here

\section{Submit Article}

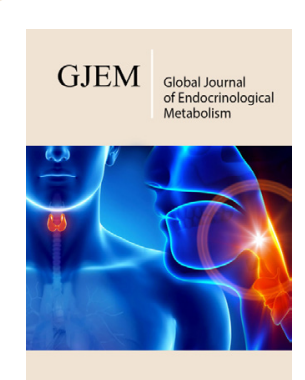

Global Journal of Endocrinological Metabolism

\section{Benefits of Publishing with us}

- High-level peer review and editorial services

- Freely accessible online immediately upon publication

- Authors retain the copyright to their work

- Licensing it under a Creative Commons license

- Visibility through different online platforms 